\title{
142. A Note on the Retino-Pulvinar and the Tecto-Pulvinar Systems in Cat
}

\author{
By David T. RYU*) \\ Department of Anatomy, Juntendo University School of Medicine, \\ Hongo, Tokyo, Japan \\ (Communicated by Teizo Ogawa, M. J. A., Nov. 12, 1976)
}

The brief reviews by several authors dramatically suggested that contradictions were treated on the species, the techniques, and the significant interpretations of the primate pulvinar in their studies. ${ }^{7), 11,21), 22)}$ On the other hand, as to the correlative pulvinar functions concerning, in particular, the visual inputs and outputs have not been satisfactorily settled in the anatomical and the physiological relationships to the present time.

Present study is conducted to identify the connections of the feline pulvinar. In the present studies, with the conventional processes by means of the modified Nauta ${ }^{19)}$ and the Fink-Heimer ${ }^{9)}$ methods, tracing the degenerating axons and terminals were performed with ten adult cats. In the experiment, each cat was operated under the Nembutal $(25 \mathrm{mg} / \mathrm{kg}$, IP) anesthesia and with aseptic conditions. The right eye-enucleation was produced by the physical thermal cauterization in four cats, and the unilateral (left, all layers) electrolytic tectal lesion was made by the stereotaxic method in other six cats. Then, the animal was transcardiacally perfused with $10 \%$ formol saline 7 days after the operation, and the brain was resected and fixed in $10 \%$ formalin for two weeks. Following this, the coronal frozen sectioning and the selective silver impregnation techniques were employed to determine the ensuing axonal degenerations which demonstrated the central retinal and the ascending tectal projections into the pulvinar (PUL), respectively.

Many earlier experiments ${ }^{4), 10), 16)}$ described that the retino-pulvinar system in the primary retinal projections was not noted with definite termination, but was indicated only a part of passage in the pulvinar complex. While in this experiment, which has precisely investigated such a similar pattern of degenerating fibers, there occurred no preterminals from the optic fibers (OF) into any part of the pulvinar complex, after eye-enucleation. However, a stream

*) The author, has legally changed the spelling of his name to D. T. Ryu. For consistency this form will be used henceforth, although on the previous papers his name is spelled D. S. Liu. 
of fiber bundle passing via the caudal pulvinar into the pretectum (PR) was always evident. Moreover, some additional retinal efferent fibers were markedly scattered and terminated bilaterally on the pretectum, the dorsal part of lateral geniculate body (GLD), the superior colliculus most particularly around the lateral region of the superficial layers, and a few preterminals appeared on the ventral part of lateral geniculate body (GLV) contralateral to the enucleation side.

On the other hand, when the varying lesions made were restricted in the superior colliculus (medial, middle, and lateral portions), the tecto-pulvinar system in the ascending tectal projections was obviously proven as the certain tectal efferent fibers ipsilaterally running through the pretectum into the caudal and medial area of the inferior pulvinar (PI), and this is in accordance with the previous report. ${ }^{17)}$ Besides these, a number of the other ascending tectal fiber systems were ipsilaterally distributed along the collicular brachial region projecting to the pretectum, the ventral part of lateral geniculate

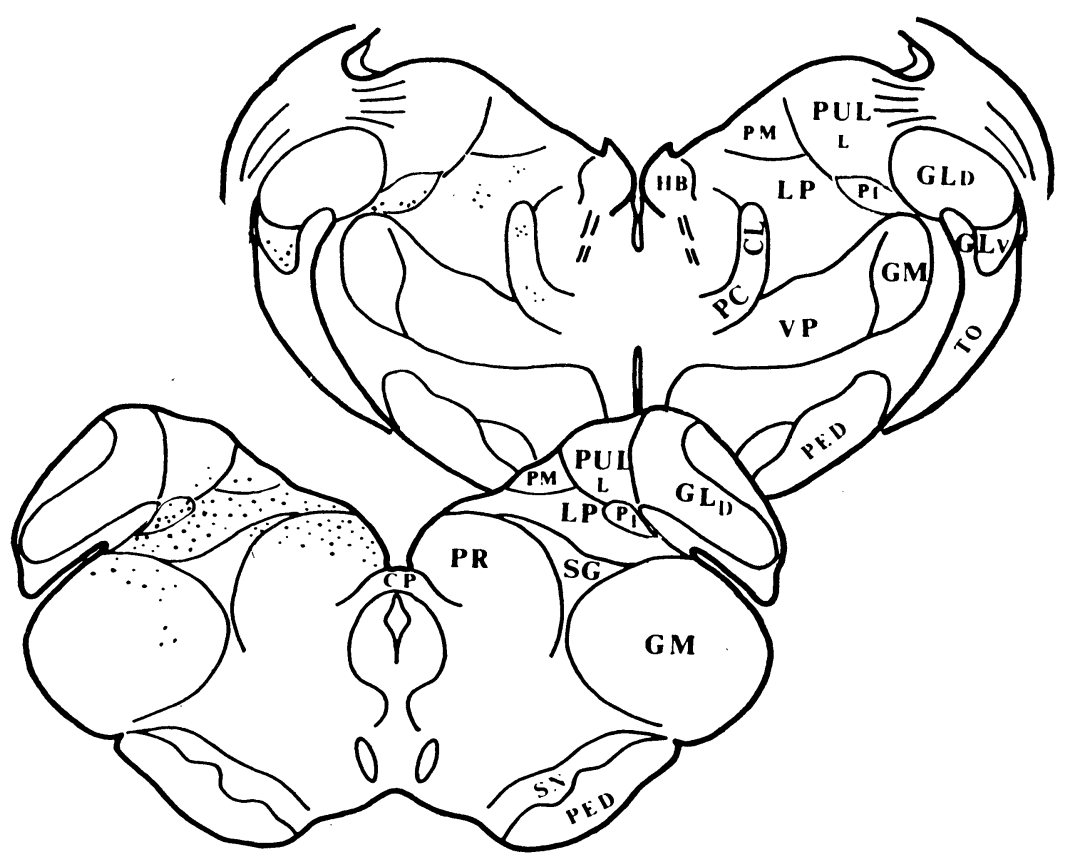

Fig. 1. This illustration, the serial coronal section drawings, was traced to demonstrate the tecto-pulvinar system and the additional tectal projections distributed onto the other thalamic nuclei. Black dots show the degenerating preterminals. CP: posterior commissure, HB: habenula, L: lateral pulvinar, PED: cerebral pednucle, PM: medial pulvinar, SN: substantia nigra, VP: posterior ventral nucleus, TO: optic tract. 


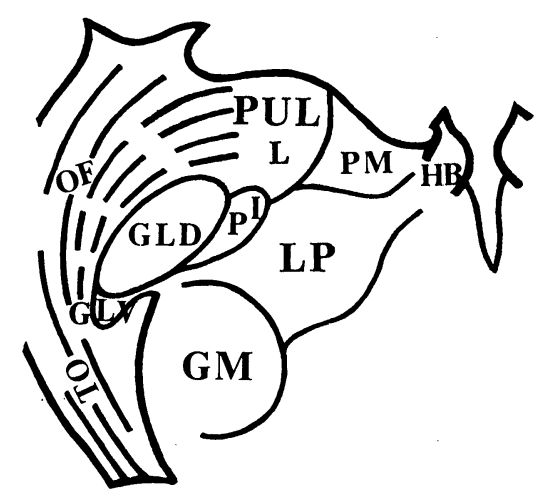

Fig. 2. This illustration, a perspective drawing of the semi-coronal section plane cutting through the pulvinar (dorsal thalamus), is shown to depict three subdivisions of L, PM, and PI of the pulvinar complex, in the feline homologue used in this study.

Abbreviations are found in the text.

body (GLV), the rostral part of medial geniculate body (GM), the suprageniculate nucleus ( $\mathrm{SG}$ ), the caudal-half of posterior lateral nucleus (LP), the lateral central nucleus (CL), and the paracentral nucleus (PC). Special concern for the tecto-pulvinar system, recently, has been well demonstrated, and agreement is reached to the fact in the cat, ${ }^{2,17), 20)}$ the monkey, ${ }^{6}$ the bushbaby, ${ }^{11)}$ the tree shrew, ${ }^{14}$ the opossum, ${ }^{5,18)}$ the squirrel, ${ }^{1)}$ and the rat. ${ }^{3)}$ But it is rarely found in the rabbit. ${ }^{23)}$ Present result of the tecto-pulvinar system is diagrammatically shown in the illustration (Fig. 1). In addition, the configuration of the pulvinar complex dividing into three subdivisions (L, PM, and PI) is depicted in the illustration (Fig. 2) which has been confirmed in this study and compared in some mammals. ${ }^{22), 24)}$

Of relations so far studied, the account findings of this experiment have therefore been analized to infer that the inferior pulvinar in the pulvinar complex is possible to involve in the integration of the effective input and output between the retina and the superior colliculus. However, a large number of variable physiological literature $^{12), 15)}$ has reported valuable data with respect to the visual perception for some time. Particularly considered, the present experimental evidence, it is to be hoped that the pulvinar functional unit regarding the Clare-Bishop area ${ }^{8)}$ of the association cortex is available to realize the visual relay feature in the mammals. Subsequently, the visual cortex (striate, parastriate cortices) forming the corticopulvinar system is also required to re-evaluate with some other tentative methods in the future.

Summary. With anterograde degeneration, the topographical 
terminals of pulvinar coming from the retina and the superior colliculus were examined. The findings suggest that the inferior pulvinar (Posterior nucleus, Hinterkern) clearly received some ascending tectal fibers, ipsilaterally. By contrast, the evidence of the retinopulvinar system was untraceable. There were found bilaterally the retino-geniculate and the retino-tectal projections. Since, the inferior pulvinar emanates its efferents into the secondary visual area of the temporal cortex..$^{13)}$ Therefore, the inferior pulvinar is like the intrinsic and extrinsic nucleus. Possible functions concerning the visual impacts, to and fro, apparently exist.

Acknowledgements. This investigation was supported in part by Mitsukoshi Prize of Medicine Junior of 1974.

\section{References}

1) Abplanalp, P.: Brain, Behav., Evol., 3, 155 (1970).

2) Altman, J., and Carpenter, M. B.: J. Comp. Neur., 116, 157 (1961).

3) Antonetti, C. M., and Webster, K. E.: 10th Int. Congr. Anat., Tokyo Ed., p. 185 (1975).

4) Barris, R. W., Ingram, W. R., and Ranson, S. W.: J. Comp. Neur., 62, 117 (1935).

5) Benevento, L. A., and Ebner, F. F.: Brain Res., 18, 171 (1970).

6) Benevento, L. A., and Fallon, J. H.: J. Comp. Neur., 160, 339 (1975).

7) Chow, K. L.: J. Comp. Neur., 93, 313 (1950).

8) Clare, M. H., and Bishop, G. H.: J. Neurophysiol., 17, 271 (1954).

9) Fink, R. P., and Heimer, L.: Brain Res., 4, 369 (1967).

10) Garey, L. J., and Powell, T. P. S.: J. Anat., 102, 189 (1968).

11) Glendenning, K. K., Hall, J. A., Diamond, I. T., and Hall, W. C.: J. Comp. Neur., 161, 419 (1975).

12) Godfrain, J. M., Meulders, M., and Veraart, C.: Brain Res., 15, 552 (1969).

13) Graybiel, A. M.: Brain Res., 44, 99 (1972).

14) Harting, J. K. W., Hall, W. C., Diamond, I. T., and Martin, G. F.: J. Comp. Neur., 148, 361 (1973).

15) Hubel, D. H., Levay, S., and Wiesel, T. N.: Brain Res., 96, 25 (1975).

16) Laties, A. M., and Sprague, J. M.: J. Comp. Neur., 127, 35 (1966).

17) Liu, D. S.: 10th Int. Congr. Anat., Tokyo Ed., p. 182 (1975).

18) Martin, G. F.: J. Comp. Neur., 135, 209 (1969).

19) Nauta, W. J., H., and Gygax, P. A.: Stain Tech., 29, 91 (1954).

20) Niimi, K., Miki, M., and Kawamura, S.: Okajimas Fol. anat. jap., 47, 269 (1970).

21) Papez, J. W.: Arch. Neurol. Psychiat., 41, 276 (1939).

22) Rioch, D. M.: J. Comp. Neur., 49, 1 (1929).

23) Tarlov, E. C., and Moore, R. Y.: J. Comp. Neur., 126, 403 (1966).

24) Von Monakow, C.: Arch. Psychiat. Nervenkr., 27, 1 (1895). 